\title{
Material properties of water- swelling material used as a water cutoff treatment material at waste landfill sites
}

\section{$\operatorname{AUTHOR}(\mathrm{S})$ :}

Inazumi, Shinya; Wakatsuki, Tadashi; Kobayashi, Masakatsu; Kimura, Makoto

\section{CITATION:}

Inazumi, Shinya ... [et al]. Material properties of water-swelling material used as a water cutoff treatment material at waste landfill sites. Journal of Material Cycles and Waste Management 2010, 12(1): 50-56

\section{ISSUE DATE:}

2010-04

URL:

http://hdl.handle.net/2433/147072

\section{RIGHT:}

The final publication is available at www.springerlink.com; This is not the published version. Please cite only the published version.; この論文 は出版社版でありません。引用の際には出版社版をご確認ご利用くだ さい。 


\title{
Material properties of water swelling material used as water cut-off treatment material at waste landfill sites
}

Shinya Inazumi ${ }^{1 *}$, Tadashi Wakatsuki ${ }^{2}$, Masakatsu Kobayashi ${ }^{3}$ and Makoto Kimura ${ }^{4}$

\begin{abstract}
:
Water-swelling material is a fluid sealant obtained by blending high absorbency polymer, a filler and a solvent by using a synthetic resin elastomer as the base material. In this research, we have studied the composition of water-swelling material, the extent of swelling, strength of the water swelling-material and the long-term performance of swelling material used as jointed water cut-off treatment material at waste landfill sites, by conducting various experiments. One of the examples of the results is that the adjustment of the degree of etherification of high absorbency polymer which is a component of the water-swelling material and the resin content of the synthetic elastomer contribute to the improvement of swelling of the sealant and strength of the swelling material. Further, as time passes, the strength of the water-swelling material shows a tendency to become stabilized and it was confirmed that it had sufficient pressure-resistance in coastal landfill sites, where its application as water cut-off treatment material is being considered.
\end{abstract}

\footnotetext{
${ }^{1}$ Assistant Professor, Graduate School of Engineering, Kyoto University

${ }^{2}$ Lead Engineer, Nihon Chemical Paints Co., Ltd.

${ }^{3}$ Director, Nihon Chemical Paints Co., Ltd.

${ }^{4}$ Professor, Innovative Collaboration Center, Kyoto University

* Corresponding author
} 


\section{Introduction}

Water-swelling material is a fluid sealant obtained by blending high absorbency polymer, a filler and a solvent by using a synthetic resin elastomer as the base material. In the field of civil engineering, water-swelling materials are widely used as water cut-off treatment material for increasing water cut-off properties at the joint section of steel sheet piles or steel pipe sheet piles (see Fig. 1). 1,2,3 Further, the water-swelling material coated or pasted to the joint section swells on contact with ground water, blocks the water passage gaps and allows water cut off at the joint section.

Recently, the "H-jointed steel pipe sheet piles with an $\mathrm{H}-\mathrm{H}$ joint", which is one of the newly developed methods for high water cut off, is being tried for application of water-swelling material for water cut-off treatment of the joints section. In a series of research projects, one can see a number of reports regarding the performance of water cut-off steel pipe sheet piles making use of an $\mathrm{H}-\mathrm{H}$ joint, using water-swelling material for adhesion. ${ }^{3,4}$ For example in plain water or artificial sea water (3\% saline), low hydraulic conductivity of the order of $1 \times 10^{-8} \mathrm{~cm} / \mathrm{s}$ has been clearly confirmed. Peeling off or the ability of water cut off of the water-swelling material at the field has been studied and good results have been reported in general.

In this paper, we have carried out studies on the composition of water-swelling material and the strength of the swelling membrane, which is used for water cut-off treatment of the joint section of steel sheet piles or steel pipe sheet piles, by conducting various experiments for the purpose of improving the swelling ability and making it stronger. Further, the long-term performance of water-swelling material used at the joint section of jointed sheet piles as water cut-off treatment material was also considered regarding the relation between the change of the strength of the swelling material with the elapsed time and pressure 
resistance.

\section{Historical background of water-swelling material}

The water extracted from a dried film of water-swelling material fulfills the Food Sanitation Law Standards and is not harmful to the environment. At present, the composition of frequently used water-swelling materials (hereafter referred to as "current water-swelling material") is such that when it is soaked in plain water or sea water for 24 hours, it swells up to 15 - 30 times and 5 - 7 times, respectively, in terms of weight ratio. Thus, the current waterswelling material has extremely high swelling ability in plain water, nevertheless, the swelling percentage in sea water is $1 / 6-1 / 3$ of that in plain water. Further, there is a tendency for the strength of the swelling material film (strength of water-swelling material after swelling) to be lower in plain water due to the effect of the water temperature. Because of this type of swelling and the strength properties of the swelling-type material, water-swelling material has, thus far, been used mainly as temporary water cut-off material. Here, the improvement in the swelling properties of the water-swelling material and the strength of the swelling material are not restricted only to increases in the water cut off at the joint section of the steel pipe sheet pile or steel sheet pile, but they may be contributing to several other applications of water-swelling material.

Representative examples of the application of water-swelling material includes vertical water cut off wall (barrier) built from steel sheets pile or steel pipe sheet pile in costal landfill sites. The vertical water cut-off property of steel sheets pile or steel pipe sheet piles is manifested by the swelling effect of water swelling material previously coated or pasted at the joints before setting up (see Fig. 1). ${ }^{1,2,3}$ While employing the water swelling material for 
water cut-off treatment of joints, it may be used in the form of a sheet pasted inside the joint (swelling-type sheet) or it may be used as a coated sealant. Depending upon the situation, it is possible to select the appropriate form of the material. Further, it is possible to prevent peeling off by synthesizing a swelling-type paint that adheres strongly to the steel. On the other hand, the water permeability factor of swelling-type material itself and that of the steel or paint are not different and both are of the order of $1 \times 10^{-9} \mathrm{~cm} / \mathrm{s}^{3}$

\section{Swelling properties of the water-swelling material}

\section{Swelling test}

Here, the swelling properties of the water-swelling material were studied for various compositions, with water of different properties, different temperature and different $\mathrm{pH}$, by designing individual tests.

The procedure for swelling tests was as follows:

(i) A definite quantity of water-swelling material was dried, it was converted into a $2 \mathrm{~mm}$ thick sheet and a test piece sized $2 \mathrm{~cm} \times 2 \mathrm{~cm}$ was prepared.

(ii) The initial weight of the test piece was measured and it was soaked in a water tank having various qualities of water at various temperatures.

(iii) After soaking for 48 hours, it was taken out and the weight was measured.

(iv) Swelling ratio (= weight after soaking / initial weight) was calculated.

The swelling ratio has been calculated by weight due to difficult in measuring volume of the water-swelling material after swelling. The swelling ratio by volume almost equaled $70 \%$ of it by weight, as a result of a preliminary test on swelling ratio of water-swelling material. 


\section{Composition and swelling ratio}

Swelling mechanism of the water-swelling material depends mainly on the expansion of the high absorbency polymer (polymeric material designed to hold a large quantity of water). We focused on the etherification (degree of substitution; DS value) of the polymer that is blended, and swelling experiments were conducted in the case of water-swelling material blended with polymers having different DS values. The DS value is an index showing the strength of bonds in the polymer structure. It is the molar quantity (number of mols) of sodium (Na) etherified (conversion into $\mathrm{Na}$ compound) corresponding to 1 unit (6 carbon atoms) of glucose $\left(\mathrm{C}_{6} \mathrm{H}_{12} \mathrm{O}_{6}\right)$ from the high absorbency polymer.

Figure 2 shows the swelling ratio of the water-swelling material soaked in plain water and artificial sea water (3\% saline) and the DS value of the high absorbency polymer). Moreover, the DS value of the high absorbency polymer used at present in water-swelling material is $0.6 \mathrm{M} / \mathrm{c} 6$. According to Fig. 2, when a polymer with a high DS value is used for blending, the swelling ratio in artificial sea water greatly increases. Especially by reforming the DS value of the high absorbency polymer to $0.9 \mathrm{M} / \mathrm{c} 6$, the swelling ratio increases 2 times of that of the current water-swelling material (High absorbency polymer DS value $=0.6$ $\mathrm{M} / \mathrm{c6}$ ). This is because the insolubility of the high absorbency polymer is enhanced due to the large number of ions present in the artificial sea water. Nevertheless, the enhancement of insolubility is moderated by the use of high absorbency polymer with a high DS value, to a certain extent. On the other hand, in plain water (which does not enhance the insolubility of the water-swelling material) it is possible to maintain the swelling ratio of the same order (27 - 29 times) even if the DS value of high absorbency polymer is increased.

Figure 3 shows the relation between the addition ratio of the high absorbency polymer (having its DS value reformed to $0.9 \mathrm{M} / \mathrm{c} 6$ in water-swelling material) and its swelling ratio. From this it is understood that the increase in the addition ratio of high absorbency polymer 
contributes to the increase in swelling of water-swelling material in an environment comprising plain water and artificial sea water. Further, in general, the addition ratio of the high absorbency polymer currently used for blending with water-swelling material (high absorbency polymer with a DS value $=0.6 \mathrm{M} / \mathrm{c} 6$ ) is $32.5 \%$ by weight.

Thus, for further improvement of the swelling ratio of the water-swelling material, it is proposed to ensure blending of high absorbency polymer having a DS value in excess of DS = $0.6 \mathrm{M} / \mathrm{c} 6$ and with more than $32.5 \%$ by weight.

\section{Salinity of soaking water, its temperature, $\mathrm{pH}$ and the swelling ratio}

The properties of the soaked water (salinity, plain water or sea water), water temperature and $\mathrm{pH}$ are supposed to greatly influence the swelling property of the water-swelling material. For this, swelling experiments were carried out by varying the conditions like the quality of soaked water, its temperature and $\mathrm{pH}$.

Depending upon whether the soaking water is plain water or artificial sea water (3\% saline) there is a large difference in the swelling ratio of the water-swelling material. On the other hand, in the case of a high absorbency polymer with a reformed DS value of around $0.9 \mathrm{M} / \mathrm{c} 6$, the swelling ratio increases a lot, especially in the case of artificial sea water (3\% saline) as stated in above, and it is possible to get a swelling ratio twice that of the value found in a case utilizing the currently used high absorbency polymer with a DS value $=0.6$ M/c6. As a result, the difference between the swelling ratio in an environment of plain water and artificial sea water declines (see Fig. 2).

As shown in Fig. 4, the temperature of the soaking water influences the swelling ratio of the water-swelling material and, especially in the case of the plain water environment, the swelling ratio shows a tendency to increase as the water temperature increases. On the other hand, increasing the temperature of artificial sea water does not improve the swelling ratio of 
the water-swelling material. The high absorbency polymer blended with water-swelling material is a high polymer electrolyte and, when it is soaked in an aqueous environment, water gets absorbed in the mesh of the high absorbency polymer and it is gelatinized (swollen condition). Further, the gelatinized high absorbency polymer dissolves in water, giving ride to a uniform polymer solution. However, the high absorbency polymer has the property of bonding with polyvalent metal ions and if polyvalent metal ions exist in the water, it forms insoluble metal salts. The formation of insoluble metal salts restricts the free movement of the molecules, and as a result, only gel formation (swelling) unidirectional water absorption into the high absorbency polymer occurs. Moreover, increasing the water temperature enhances the quantity of water absorbed into the high absorbency polymer (swelling is enhanced) more. On the other hand, in an artificial sea water environment, as the ionic concentration is high, the water content that the high absorbency polymer can absorb may reduce (insolubility is enhanced and swelling becomes less). Thus, the insolubility of high absorbency polymer is enhanced and, when the swelling ratio of the water-swelling material itself is small (under the artificial sea water environment), the increase in the swelling ratio may also be prevented as the temperature goes up.

Figure 5 shows the relation between $\mathrm{pH}$ of the soaking water and of the swelling ratio of the water-swelling material. From this, it is understood that the water- swelling material has a tendency to have a lower swelling ratio in a strongly acidic or strongly alkaline area. However, if the $\mathrm{pH}$ is in the area of $4-12$, the influence of $\mathrm{pH}$ on the swelling ratio is less and thus in the actual use of water-swelling material, $\mathrm{pH}$ of soaked water does not have a great influence.

\section{Swelling ratio and concentration of chemical substances of the soaking water}

Assuming that the water-swelling material is going to be used as water cut-off material for 
coastal waste-disposal sites; the swelling properties of the water-swelling material were studied in various harmful chemical substances that are supposed to be present in reclaimed landfills. Further, as it is not possible to identify all the chemical substances that are found in reclaimed landfills, the study was conducted in water containing chemical substances shown in Table 1.

Table 1 also shows the swelling ratio of water-swelling material obtained in the water containing chemical substances. From this, it could be confirmed that even in soaking water containing heavy metals, the water-swelling material shows swelling of the same order as that in the case of plain water (see Table 1(a)) and the deterioration of the swelling material could not be confirmed. Thus, it can be concluded that heavy metals contained in the soaking water do not have a large influence on the swelling ratio of the water-swelling material.

On the other hand, when organic solvents are contained in the soaking water, the synthetic resin elastomer (which is the base material for the water-swelling material), gets soaked in the solvent, when the organic solvent is in a saturated concentration. Due to this, the water-swelling material collapses and this disables the application of the water-swelling material when the organic solvent is in a saturated concentration. Further, swelling is also not possible in a saturated concentration of organic solvents. On the other hand, the influence of organic solvents on swelling of the water-swelling material is not at all seen in soaking water containing organic solvents to the extent of $2.0 \mathrm{~g} / \mathrm{L}$, and sufficient swelling takes place (see Table 1(b)). Moreover, deterioration of the water-swelling material was also not seen in the condition of a concentration around $2.0 \mathrm{~g} / \mathrm{L}$. 


\section{Strength characteristics of water-swelling material}

\section{Water-swelling material strength test}

Water-swelling material strength means the strength of the material when the water swelling-material is in a swollen condition. Swelling material strength of the water-swelling material greatly influences the resistance to water (hydraulic) pressure and long-term endurance. Thus, a study was conducted from various viewpoints for improving the strength of swelling material, and it was concluded that the composition of water-swelling material is the factor behind this. Here, the swelling strength of the water-swelling material was measured by using a small desk testing machine (EZTEST-500N, SHIMADZU Corporation) and penetrating elastic tool (diameter $3 \mathrm{~mm}$ ) (see Fig. 6) and, the relation of the composition of the water-swelling material with the swelling strength was studied. The swelling material strength was defined as the strength required (by the penetration elastic tool with a $3 \mathrm{~mm}$ diameter), for penetration and breaking of the water-swelling material.

The procedure for the swelling film strength test was as follows:

(i) A definite quantity by weight of water-swelling material was dried, it was converted into a $2 \mathrm{~mm}$ thick sheet and a test piece sized $2 \mathrm{~cm} \times 2 \mathrm{~cm}$ was prepared.

(ii) The test piece was submerged in a water tank filled with plain water and artificial sea water at a set temperature.

(iii) After submerging for 48 hours, the penetration tool (3 mm diameter) was slowly allowed to penetrate into the water-swelling material as shown in Fig. 6 and the swelling material strength (penetration elasticity value) was measured.

\section{Composition and swelling material strength}

Synthetic resin elastomer, which is the base material for the water-swelling material, is one of 
the materials that influences the swelling film strength. Here, attention was paid to the resin content (vinyl acetate) of the synthetic resin elastomer, and swelling material strength tests were carried out in the case of water-swelling material blended with elastomer B and elastomer $\mathrm{C}$ (having a resin content 1.3 times and 1.5 times that in the synthetic resin elastomer A, which is used for blending with the current water-swelling material).

Table 2 shows the swelling ratio and the swelling material strength of the water-swelling material soaked in plain water and artificial sea water at $20^{\circ} \mathrm{C}$ water temperature. Further, Fig. 7 shows swelling material strength with the variation of the temperature of the soaking plain water or artificial sea water. Table 2 shows that the swelling ratio of the water-swelling material decreases according to the synthetic resin elastomer content blended with it. However, when blended with elastomers B or C, which have a higher resin content, the swelling material strength increases in plain water and artificial sea water. Especially water-swelling material blended with a higher quantity of synthetic resin elastomer B can increase the swelling film strength to about 2 times and 1.5 times that of the currently used water-swelling material in plain water and artificial sea water, respectively. The increase in the swelling material strength by blending with elastomer $\mathrm{B}$ and $\mathrm{C}$ is manifested in the case of both a plain water and artificial sea water environment under a water temperature of 5 $30^{\circ} \mathrm{C}$ (see Fig. 7). On the other hand, the swelling material strength blending with each elastomer shows the tendency to decrease with the increase of water temperature in the case of both a plain water and artificial sea water. Furthermore, the decrease in the strength under the artificial sea water environment may be confirmed to be larger than that under the plain water environment. However, it is thought that the strength decreasing rate of the sea water environment and that under the plain water environment are the almost the same levels. Also, no much difference in the decreasing tendency in both swelling ratio and swelling material strength was seen between two cases of plain and artificial sea water (see Figs. 4 and 7). 


\section{Long-term endurance of water cut-off treated joints}

\section{Outline of the test}

A swelling material strength test and endurance test were carried out in the case of water-swelling material, supposing its application at the joints of steel sheet piles or steel pipe sheet piles, for understanding the relation between the changes of the swelling material strength and its resistance to water pressure with elapsed time. Here, water-swelling materials used for the tests simulate the condition of being pasted on the joints of steel sheet piles and steel pipe sheet piles as shown in Fig. 1, and swelling of the water-swelling material was imitated to some extent in the joint gaps. The swelling film strength test conducted here is called a "restraint-type swelling material strength test" for differentiating it from the swelling material strength test mentioned above. The difference between the two is "whether the swelling is restrained or not", during soaking of the water-swelling material. In the restraint-type swelling material strength test, a test piece holder was prepared by pasting the water-swelling material in the form of a $2 \mathrm{~mm}$ thick sheet on two acrylic plates as shown in Fig. 8 and it was submerged in a water tank filled with plain water or artificial sea water (3\% saline). Further, swelling of the water-swelling material was restrained between the two acrylic plates. After being submerged for a set period of time, the water-swelling material was taken out from the acrylic plates and it was slowly allowed to be penetrated by the penetration elasticity tool shown in Fig. 6 (3 mm diameter) to measure the swelling film strength.

On the other hand, in the test for evaluating the relation between pressure resistance of water-swelling material and the swelling material strength (see Fig. 9), water-swelling material of thickness $1,1.2,1.4$ and $2 \mathrm{~mm}$ was pasted on both sides of the flange tool of the pressure resistance container (gap: $10 \mathrm{~mm}$ ) and the pressure resistance container was submerged in a water tank filled with plain water and after 15 - 30 days have passed, pressure 
was applied on the pressure resistance container in a step-wise manner and the pressure required for a leakage of air was measured. The pressure of the previous step was considered to be the pressure resistance. At the same time, by measuring the swelling material strength by using a penetration elasticity tool for a test piece after the pressure resistance test, the relation between the pressure resistance of water-swelling material and the swelling material strength under the condition of restricted swelling in the flange tool was worked out. Now the use of water-swelling material of various thicknesses in the tests and tests conducted for arbitrary submerging periods are for working out the relation between restricted swelling film strength at various levels and pressure resistance of the water-swelling material.

\section{Variation of swelling material strength with elapsed time}

Figure 10 shows the elapsed time of the film strength under the restricted swelling condition of water-swelling material of $2 \mathrm{~mm}$ thickness obtained from a restraint-type swelling film strength test. In the initial period of water submerging, the water-swelling material maintains its swelling film strength which it had prior to submerging. As time passes, the water content penetrates the entire water-swelling material and the swelling film strength shows a decreasing tendency. A reduction in the restricted swelling film strength can be attributed to the reduction of density (cross linking density) of the water-swelling material due to a swelling of the high absorbency polymer in the water-swelling material in the stage where the water spreads into the water-swelling material. On the other hand, water-swelling material submerged into artificial sea water has a higher value of swelling material strength as compared to that in plain water. This may be because the quantity of swelling in water-swelling material is less in a sea water environment, which contains electrolytes, than in a plain water environment. Therefore, the density of water-swelling material is higher than in a plain water environment. In other words, although water-swelling material exposed to a sea 
water environment has a lesser quantity of swelling as compared to that exposed to plain water, the density of water swelling sealant material exposed to sea water is comparatively high and the swelling material strength of water-swelling material is higher than that of the material submerged for the same time in a plain water environment.

Further, as explained earlier, by varying the composition ratio of the high absorbency polymer, filler and solvent, and water-swelling material, it is possible to increase the swelling material strength (improvement of water-swelling material) of water -swelling material.

\section{Relation between swelling material strength and pressure resistance}

Figure 11 shows the relation between the swelling film strength and pressure resistance under the restricted swelling condition for water-swelling material submerged in plain water for 15 30 days. From this, it is understood that as the swelling film strength increases, the pressure resistance of water-swelling material also increases and when the swelling film strength of water-swelling material under a restricted swelling condition is more than $1.0 \mathrm{~N}$, the pressure resistance is $0.5 \mathrm{MPa}$ or more and when the swelling film strength under a restricted swelling condition becomes $0.2 \mathrm{~N}$ or less the pressure resistance reduces to $0.1 \mathrm{MPa}$. Here, in case of a coastal landfill with $2 \mathrm{~m}$ managed water level ${ }^{5}$ (difference of water level on inside and outside of the landfill); the pressure resistance required for water-swelling material at the joint for water cut off is about $0.05 \mathrm{MPa}$, even after considering the dangerous level (water level difference of $5 \mathrm{~m}$ ). Thus, if the swelling film strength is maintained at or above $0.2 \mathrm{~N}$, the water-swelling material can maintain a sufficient water cut-off effect for a pressure of 0.05 MPa. Further, in the restraint swelling-type elasticity experiments in the case of water-swelling material, in a period of 5 years, the restricted swelling film strength of water-swelling material shows an asymptotic tendency near 1.6 and $0.95 \mathrm{~N}$ in sea water and plain water (see Fig. 10) and thus a swelling film with a stable strength and pressure 
resistance even for a long period is expected. However, for evaluation of the endurance of the water-swelling material in more detail, it is necessary to continue these experiments.

\section{Conclusions}

In this paper, experimental studies were carried out in the case of the composition of water-swelling material, its swelling and swelling material strength. Further long-term performance of water-swelling material used for water cut-off treatment of $\mathrm{H}$-jointed steel pipe sheet piles with an $\mathrm{H}-\mathrm{H}$ joint was discussed from the point of the variation of the swelling film strength and pressure resistance with elapsed time.

The results obtained were as follows:

(1) In case of water-swelling material blended with high absorbency polymer with higher etherification value (DS value), the swelling ratio is very high in artificial sea water. Especially, by reforming the DS value of the high absorbency polymer to $0.9 \mathrm{M} / \mathrm{c} 6$, swelling ratio that is 2 times the value of that of the currently used water-swelling material (with a DS value of the high absorbency polymer $=0.6 \mathrm{M} / \mathrm{c} 6$ ) can be obtained in an artificial sea water environment.

(2) An increase in the water temperature of plain water influences the increase in the swelling ratio of the water-swelling material. On the other hand, the temperature of sea water does not influence the swelling ratio of the water-swelling material. Further, water-swelling material shows a tendency of lowering the swelling ratio in strongly acidic or strongly alkaline areas, but the influence of $\mathrm{pH}$ on the swelling ratio of the water-swelling material is less in the area of $\mathrm{pH} 4-12$.

(3) The quantity of synthetic resin elastomer, which is a component of the water-swelling 
material, contributes to the improvement of the swelling film strength of the water-swelling material. Especially water-swelling material blended with a higher quantity of synthetic resin elastomer B can increase the swelling film strength to about 2 times and 1.5 times that of the currently used water-swelling material in plain water and artificial sea water, respectively.

(4) The swelling film strength of water-swelling material is higher when exposed to a sea water environment as compared to that exposed to a plain water environment. Further, with elapsed time, the swelling film strength shows a tendency to stabilize. Moreover, the swelling film strength showing some stability has sufficient pressure resistance at coastal landfills.

\section{References}

1. Kamon M, Inui T (2002) Geotechnical problems and solutions of controlled waste disposal sites (in Japanese). JSCE Journal of Geotechnical Engineering 701/III-58:1-15

2. Oki T, Torizaki K, Kita H, Yoshida M, Sakaguchi Y, Yoshino H (2003) Evaluation of impermeability performance of the vertical impermeable walls by using steel sheet piles and steel pipe sheet piles (in Japanese). Proceedings of the 5th Japan National Symposium on Environmental Geotechnology 53-58

3. Inazumi S, Kimura M, Too A.J.K, Kamon M (2005) Performance of H-jointed steel pipe sheet piles with $\mathrm{H}-\mathrm{H}$ joint in vertical hydraulic cutoff walls. Proceedings of the 16th International Conference on Soil Mechanics and Geotechnical Engineering 4:2269-2272 
4. Inazumi S, Kimura M (2009) On-site verification for installation and permeability of H-jointed SPSPs with H-H joints. Proceedings of the 17th International Conference on Soil Mechanics and Geotechnical Engineering (Accepted for Publication)

5. Waterfront Vitalization and Environment Research Center (2002) Design, Construction and Management Manual for Managed Type Waste Reclamation (in Japanese). Waterfront Vitalization and Environment Research Center 


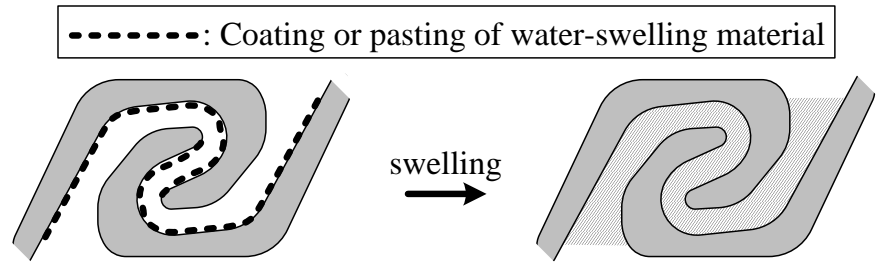

(a) Joint section of steel sheet piles
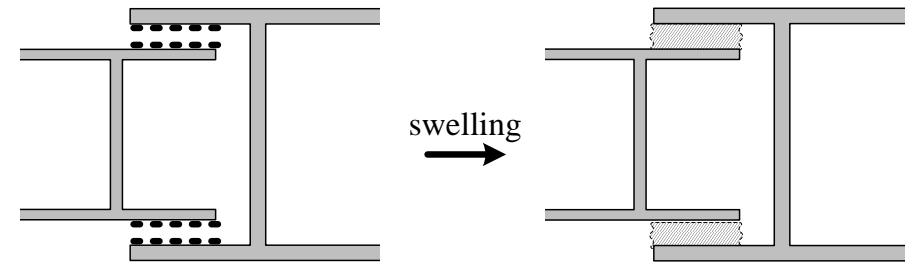

(b) Joint section of steel pipe sheet piles

Figure 1 Water cut-off treatment on joint section of steel sheet piles or steel pipe sheet using water-swelling materials

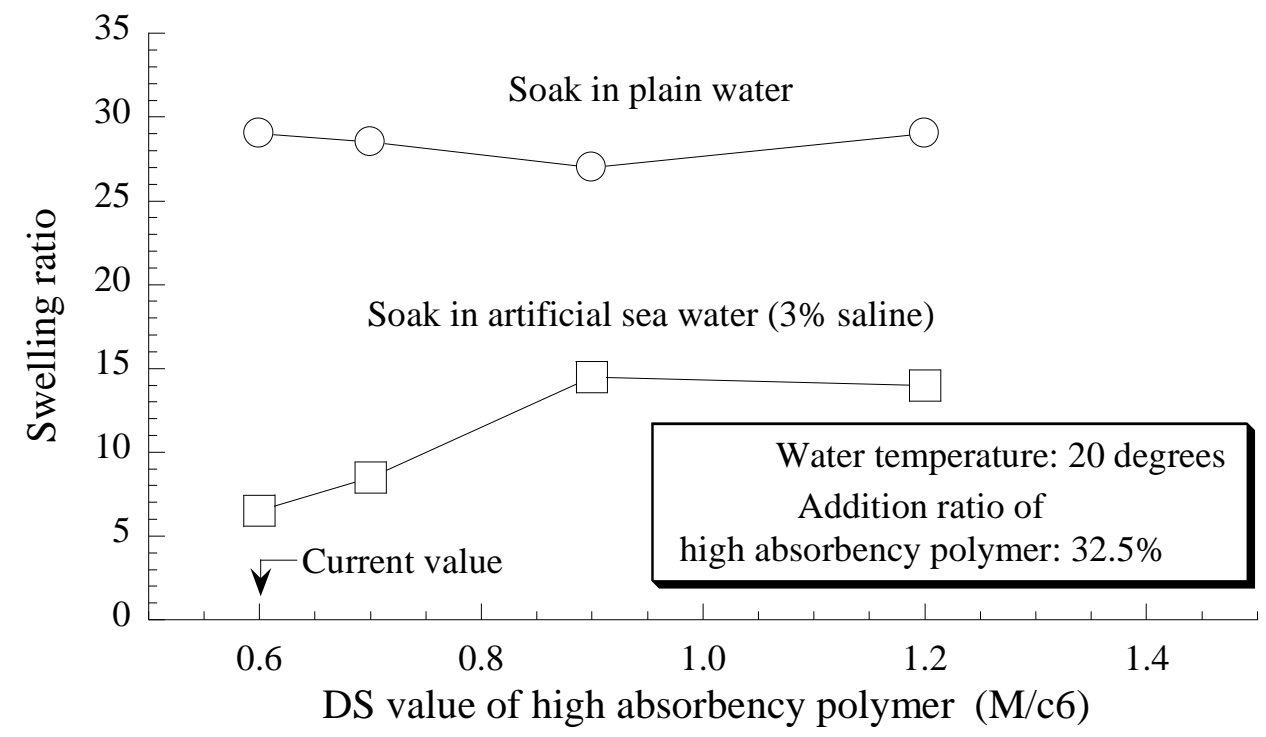

Figure 2 Relationship between swelling ratio and DS value of high absorbency polymer for water-swelling material 


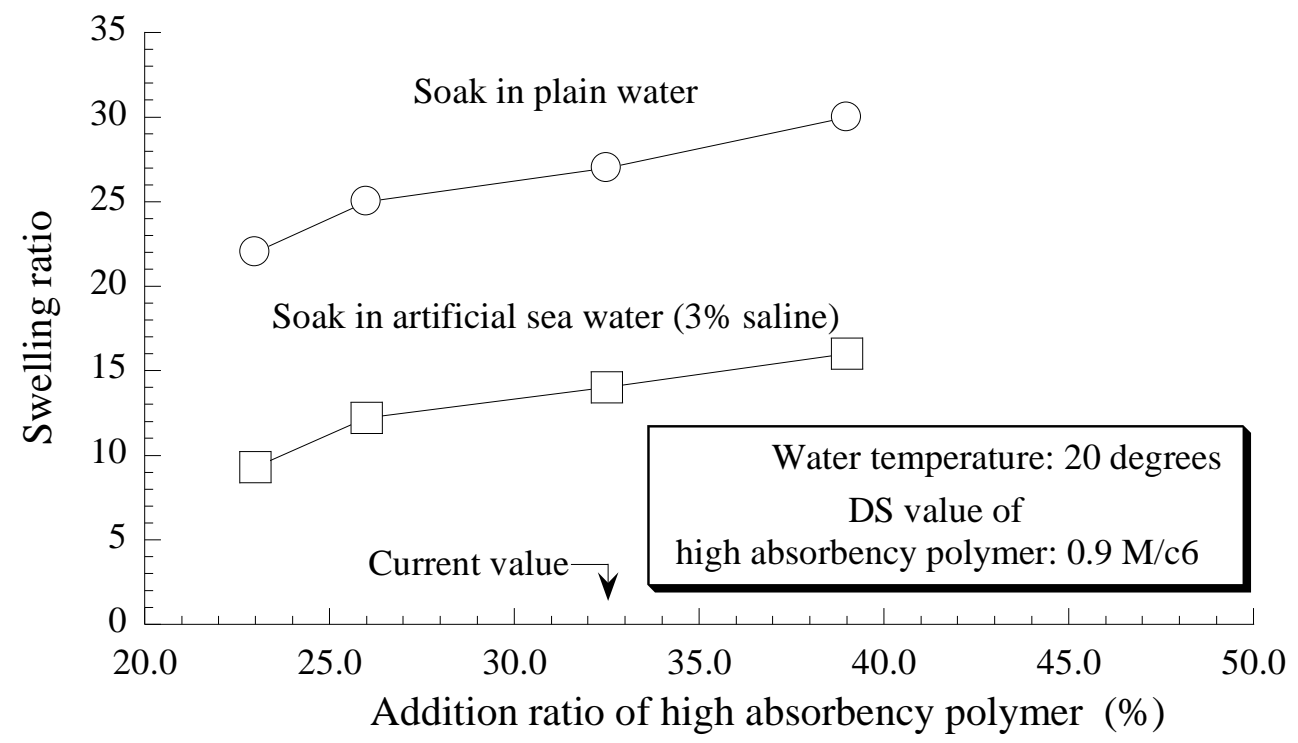

Figure 3 Relationship between swelling ratio and addition ration of high absorbency polymer for water-swelling material

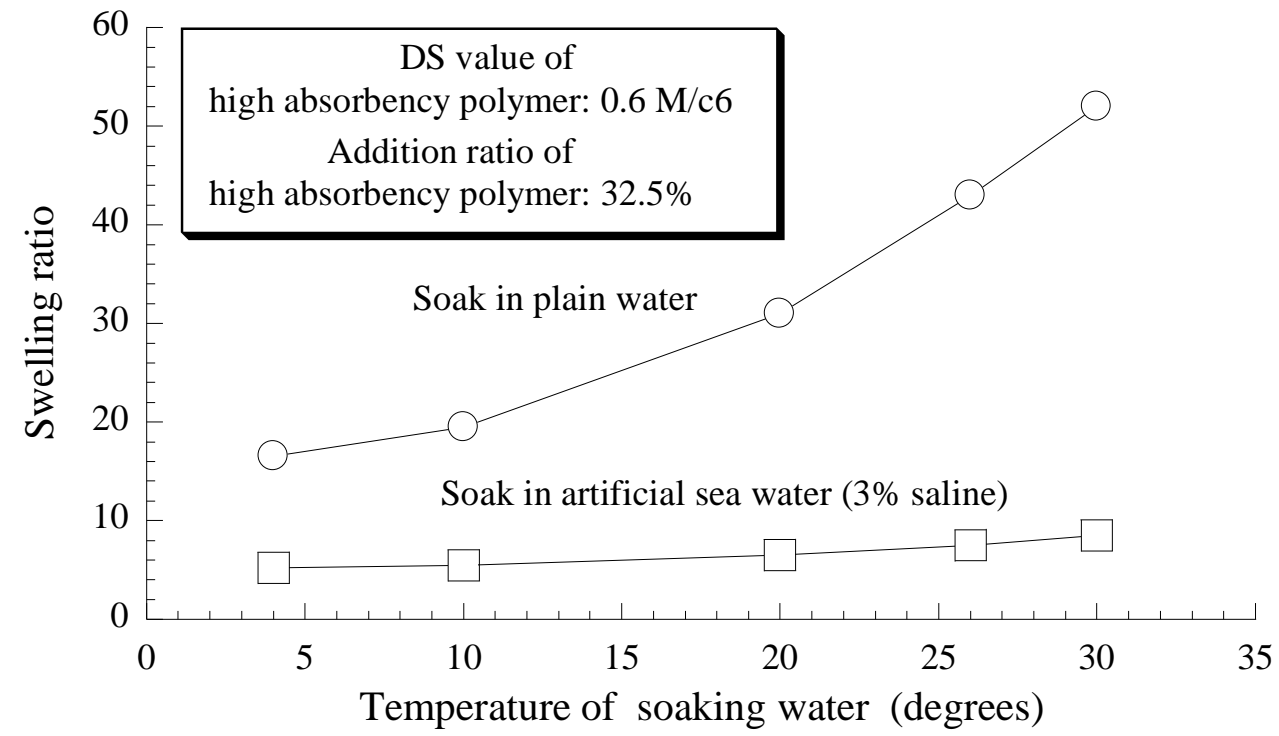

Figure 4 Relationship between swelling ratio and temperature of soaking water for water-swelling material 


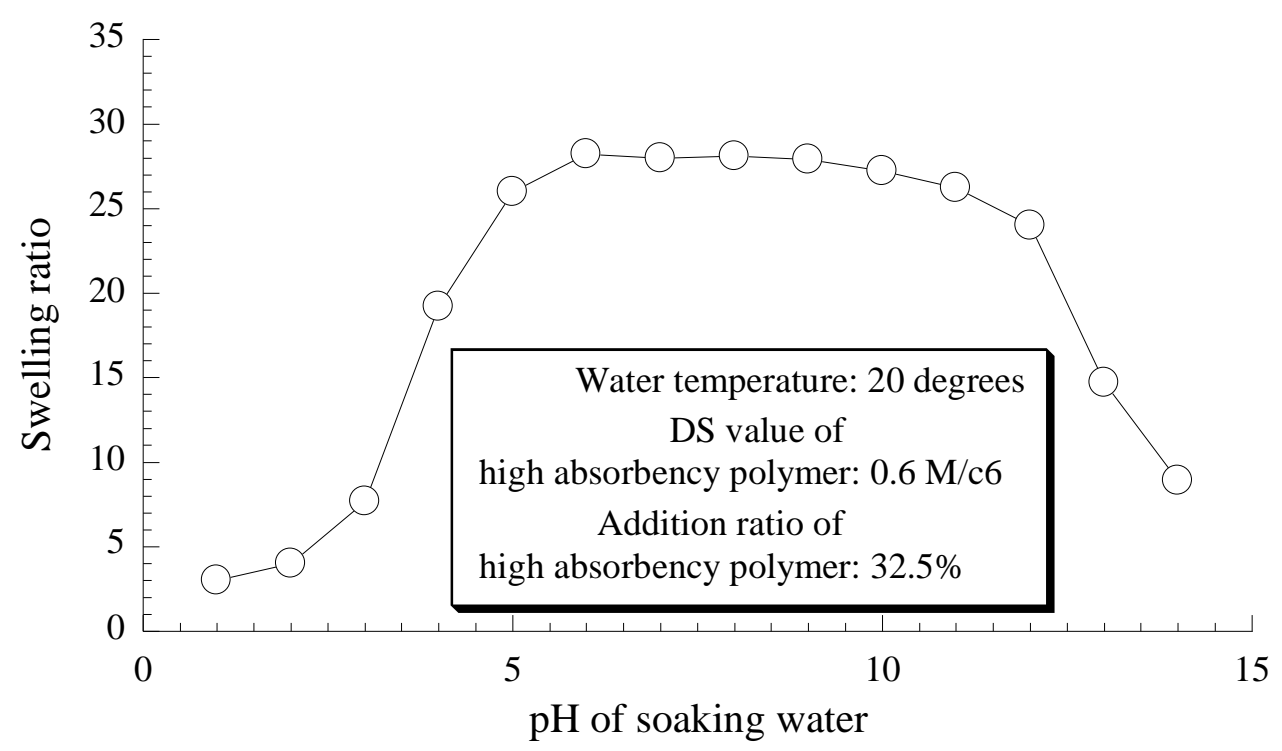

Figure 5 Relationship between swelling ratio and $\mathrm{pH}$ of soaking water for water-swelling material

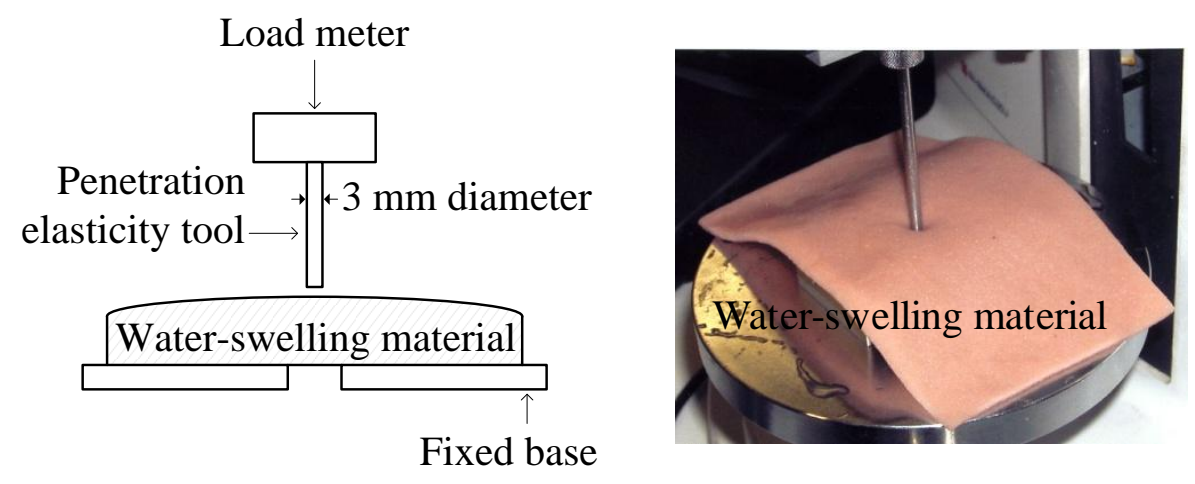

Figure 6 Simple overview of water-swelling material strength test 


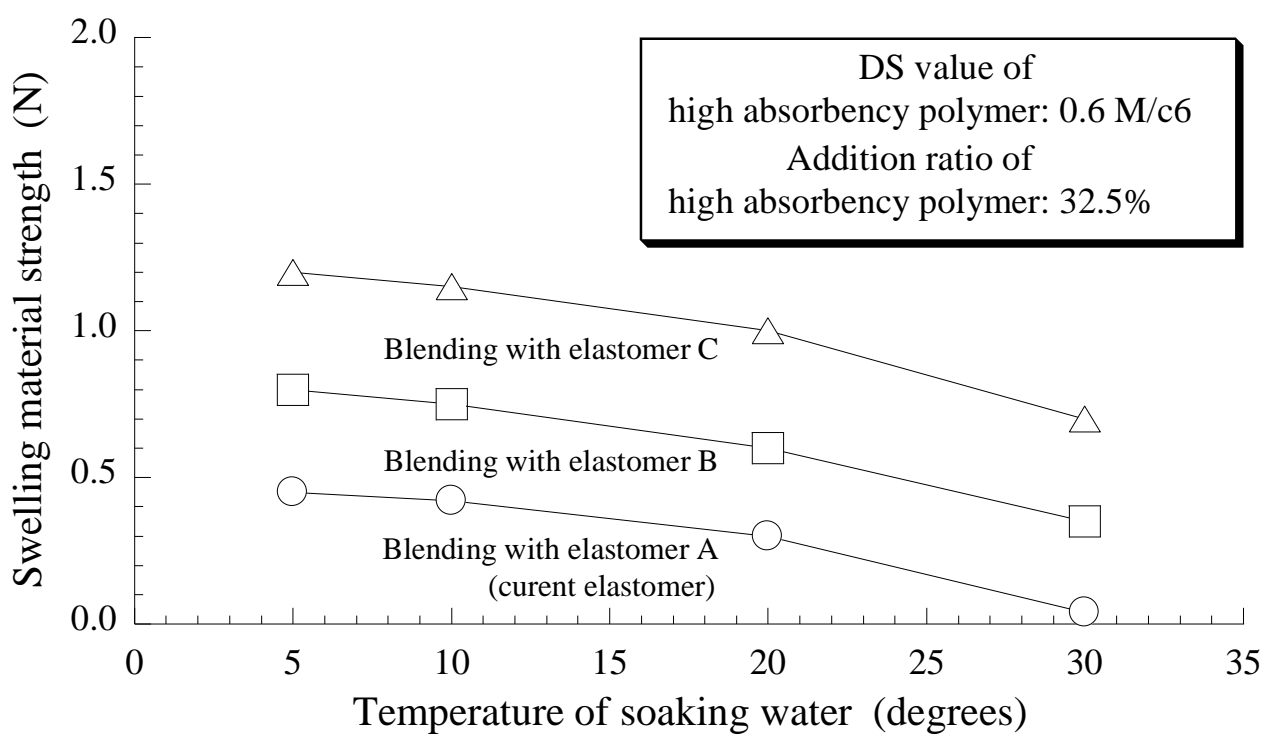

(a) Soaking in plain water

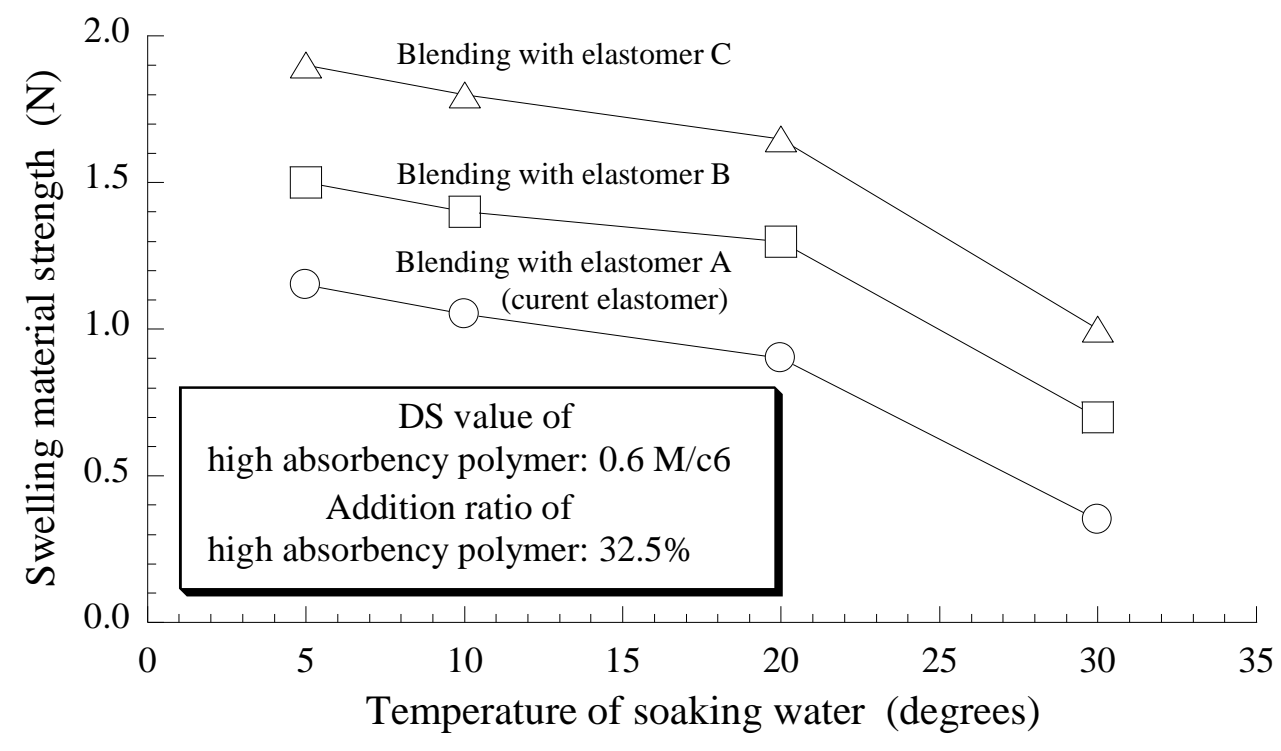

(b) Soaking in artificial sea water

Figure 7 Relationship between swelling material strength and temperature of soaking water for water-swelling material 


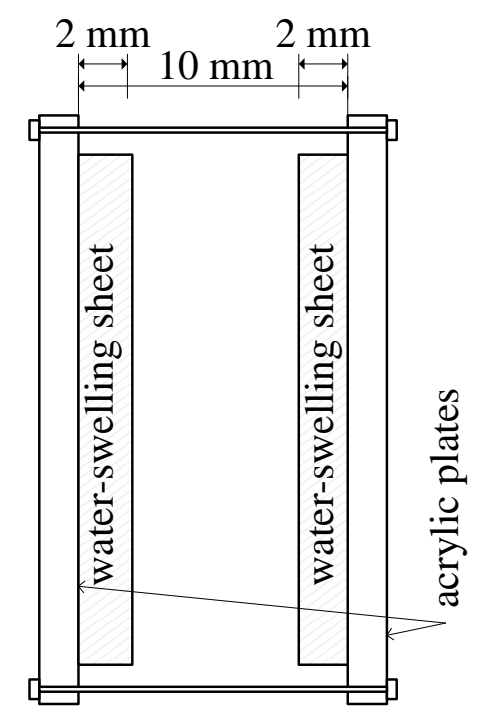

Figure 8 Swelling of water-swelling material under restraint-type swelling

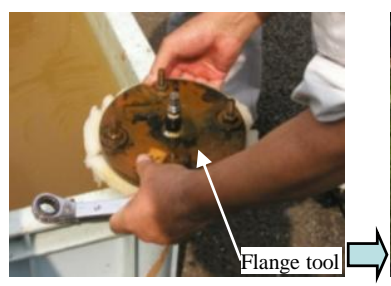

(a) Test specimen

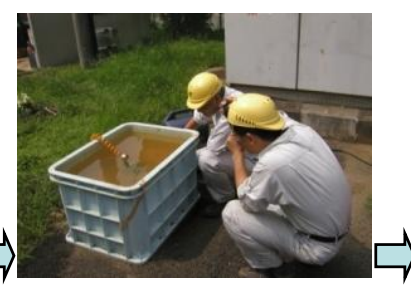

(b) Pressure resistance test

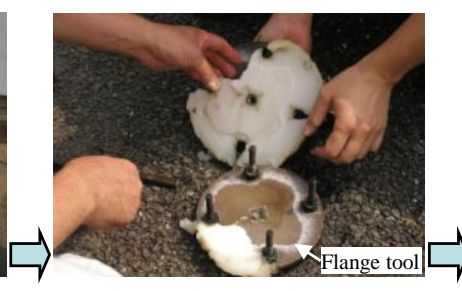

(c) Demolition

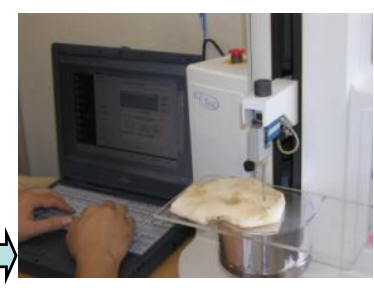

(d) Strength test

Figure 9 Evaluation chart of relation between pressure resistance of water-swelling material and swelling material strength 


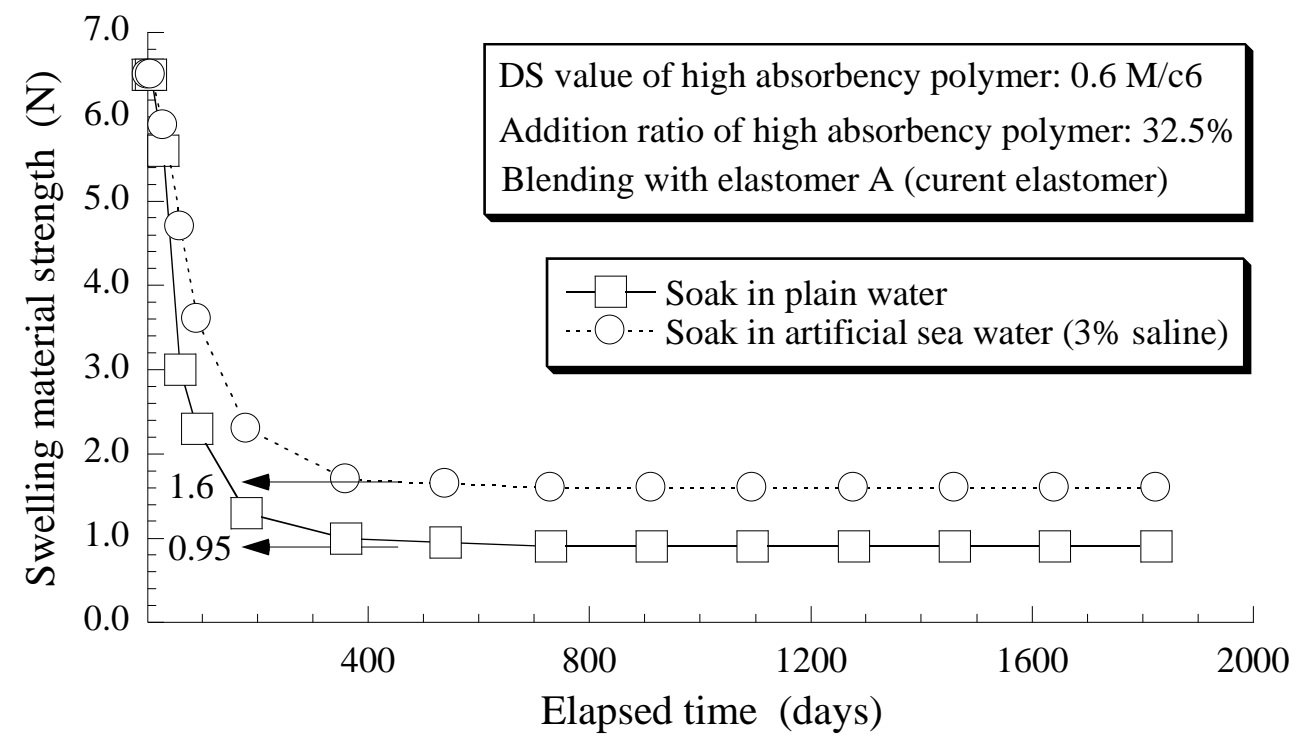

Figure 10 Change in film strength under the restricted swelling condition of water-swelling material

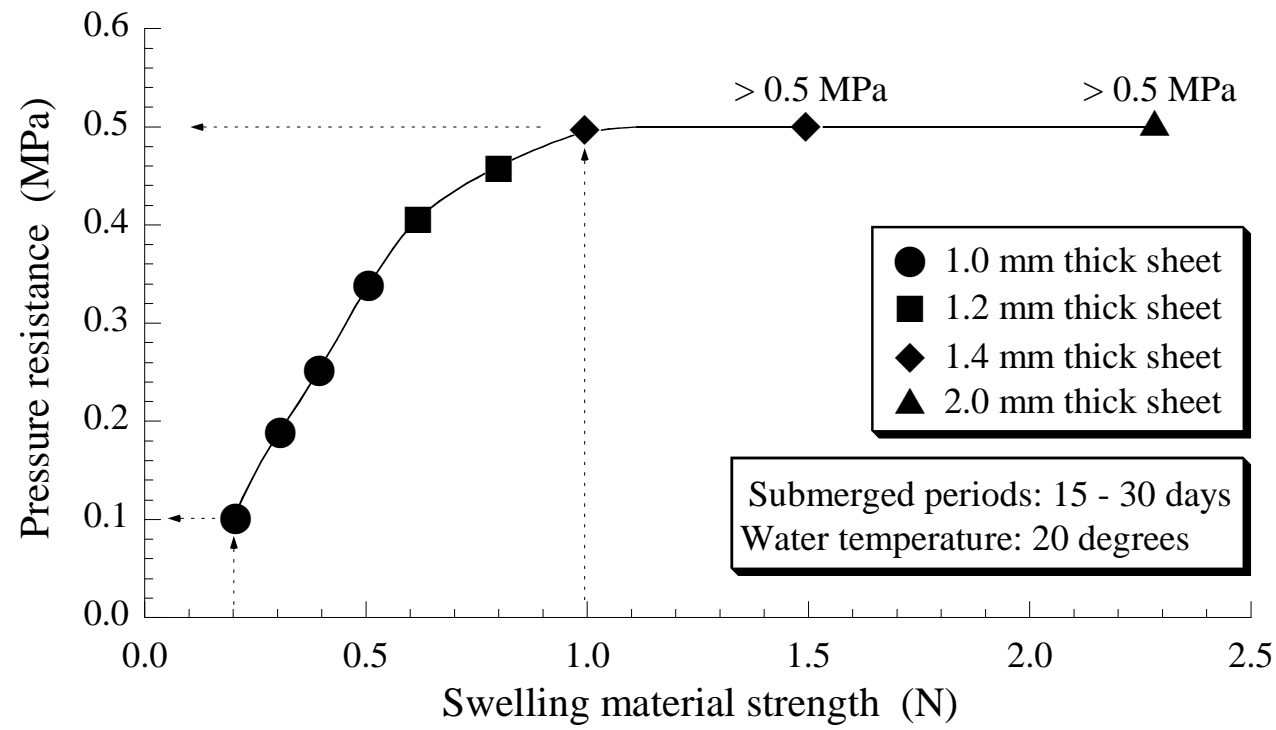

Figure 11 Relationship between swelling film strength and pressure resistance 
Table 1 Swelling ratio of water-swelling material obtained in water containing chemical substances

(a) Water containing heavy metals

\begin{tabular}{l|c}
\hline \multirow{2}{*}{ Chemicals } & $0.2 \mathrm{~g} / \mathrm{L}$ solution \\
\cline { 2 - 2 } & Swelling ratio \\
\hline Chrome oxide IV & 27.3 \\
Cadmium sulfate & 27.1 \\
Selenious acid & 25.8 \\
Lead chloride II & 28.7 \\
Mercury nitrate II & 27.3 \\
Potassium ferrocyanide & 27.5 \\
Arsenic trioxide & 28.0 \\
Thiram & 26.5 \\
Thiobencarb & 28.6 \\
Simazine & 27.0 \\
\hline \multicolumn{2}{r}{} \\
\hline
\end{tabular}

(b) Water containing Organic solvents

\begin{tabular}{l|c|c}
\hline \multirow{2}{*}{ Chemicals } & $\begin{array}{c}\text { Saturated } \\
\text { solution }\end{array}$ & $\begin{array}{c}2.0 \mathrm{~g} / \mathrm{L} \\
\text { solution }\end{array}$ \\
\cline { 2 - 3 } & Swelling ratio & Swelling ratio \\
\hline Benzene & decay & 27.3 \\
Trichlorethylene & decay & 28.6 \\
Tetrachloroethylene & decay & 29.3 \\
Dichloromethane & decay & 28.1 \\
Carbon tetrachloride & decay & 27.4 \\
Dichloroethane & decay & 28.7 \\
Trichloroethane & decay & 27.1 \\
\hline
\end{tabular}

(Swelling ratio under plain water: 28.0)

Table 2 Swelling ratio and the swelling material strength of water-swelling material soaked in plain water and artificial sea water at $20^{\circ} \mathrm{C}$ water temperature

\begin{tabular}{l|c|c|c|c}
\hline \multirow{2}{*}{ Elastomer } & \multicolumn{2}{|c|}{ Swelling ratio } & \multicolumn{2}{c}{ Strength (N) } \\
\cline { 2 - 5 } & $\begin{array}{c}\text { Plain } \\
\text { water }\end{array}$ & $\begin{array}{c}\text { Artificial } \\
\text { sea water }\end{array}$ & $\begin{array}{c}\text { Plain } \\
\text { water }\end{array}$ & $\begin{array}{c}\text { Artificial } \\
\text { sea water }\end{array}$ \\
\hline Elastomer A & 31 & 15 & 0.3 & 1.0 \\
Elastomer B & 28 & 14 & 0.6 & 1.3 \\
Elastomer C & 24 & 11 & 1.0 & 1.8 \\
\hline
\end{tabular}

